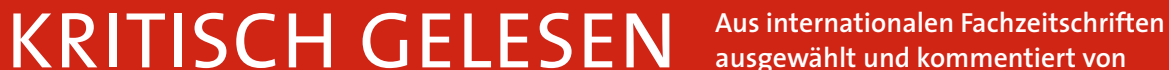

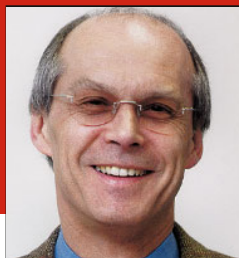

Prof. Dr. med. H. S. FüeßI Isar-AmperKlinikum, $\mathrm{KI}$. MünchenOst, Haar

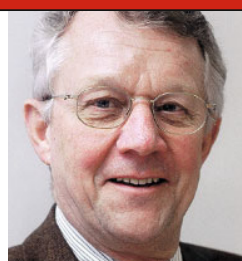

Prof. Dr. med. H. Holzgreve

Internist, Kardiologische Praxis, München

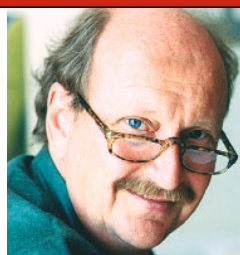

Prof. Dr. med. E. Ernst

Peninsular

Medical School,

University of Exeter/UK

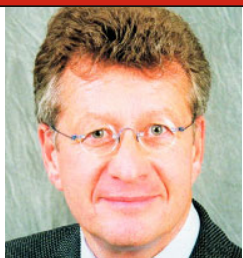

Dr. med. P. Stiefelhagen

Westerwald Krankenhaus, Hachenburg

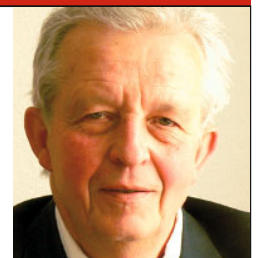

Prof. Dr. med. K. Malberg Immunologie, DresdenLoschwitz

\section{CRP: Indikator oder Ursache für ein breites Krankheitsspektrum?}

\section{Die Bestimmung des C-reaktiven Proteins (CRP) als Risikomarker für kardiovaskuläre Erkrankungen wird von einigen Fachgesellschaften propagiert. Die wissenschaftlichen Daten dazu sind aber nicht eindeutig.}

- Die Datenbasis der Analyse ist imponierend: Es handelt sich um Verlaufsuntersuchungen aus 54 prospektiven Langzeitstudien über 5,8 Jahre und 1,31 Millionen Probandenjahre bei 160309 Männern und Frauen, die zu Beginn im Mittel 60 Jahre alt und frei von kardiovaskulären Erkrankungen waren. $\mathrm{Zu}$ verzeichnen waren 10451 tödliche und nicht tödliche Komplikationen einer koronaren Herzkrankheit, 2846 ischämische, 469 hämorrhagische und 1180 nicht klassifizierte Schlaganfälle, 1659 Todesfälle aus anderen kardiovaskulären Ursachen, 10236 nicht vaskuläre und 860 nicht klassifizierte Todesfälle.

\section{Die wichtigsten Ergebnisse:}

(1) Bei logarithmischer Darstellung besteht eine lineare, signifikante Korrelation nicht nur zwischen dem CRP und zahlreichen kardiovaskulären Risikofaktoren, sondern auch zu Entzün-

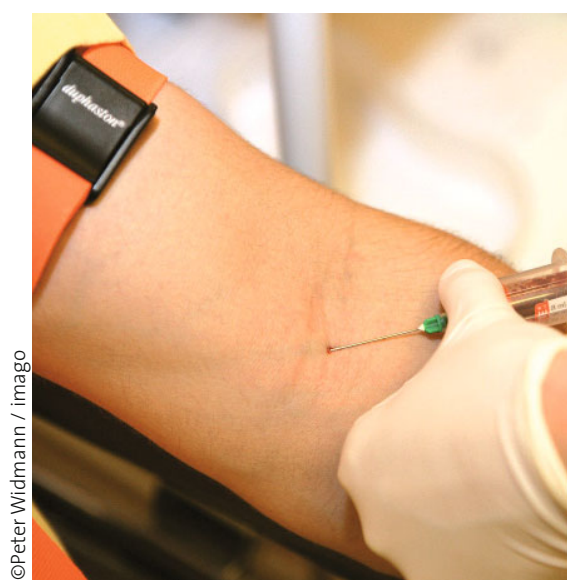

Welche Erkenntnisse lassen sich aus der Bestimmung des CRP gewinnen?

dungsparametern. Die CRP-Konzentrationen sind über Jahre vergleichbar stabil wie die Cholesterinwerte und der Blutdruck.

2 Das CRP war höher bei Frauen, Rauchern und Diabetikern und niedriger bei Alkoholkonsumenten und körperlich aktiven Patienten.

(3) Das CRP korreliert nicht nur mit Herzinfarkten, Schlaganfällen und vaskulären Todesfällen, sondern auch mit Todesfällen aus nicht vaskulären Ursachen und auf Grund maligner Erkrankungen.
4 Wenn für andere kardiovaskuläre Risikofaktoren und Entzündungsparameter adjustiert wird, schwächen sich die Korrelationen zwischen CRP und vaskulären sowie nicht vaskulären Erkrankungen erheblich ab, bleiben aber signifikant.

\section{Kommentar}

Das Plasmaprotein CRP ist ein sensitiver und schnell reagierender Indikator für Entzündungen. Die neue Analyse zeigt, dass das CRP mit einem weiten Spektrum von vaskulären und nicht vaskulären Erkrankungen signifikant und in jeweils vergleichbarer Größenordnung korreliert. Es bleibt unklar, worauf diese Beziehung zwischen CRP und vaskulären, nicht vaskulären sowie malignen Erkrankungen beruht. Der Beweis für eine kausale Verknüpfung könnte nur durch den Nachweis geführt werden, dass eine prophylaktische antientzündliche oder immunsuppressive Behandlung kardiovaskuläre und maligne Erkrankungen verhindert.

H. HolzG REVE —

\footnotetext{
- The Emerging Risk Factors Collaboration C-reactive protein concentration and risk of coronary heart disease, stroke, and mortality: an individual participant meta-analysis. Lancet 375 (2010) 132-140
} 